\title{
Nuevos mundos y viejas lenguas. El problema de la transmisión del conocimiento en la literatura utópica de los siglos XVI y XVII
}

\author{
Susana GÓMEZ LÓPEZ
}

\begin{abstract}
RESUMEN
Ni la Antigüedad clásica ni la filosofía medieval fueron ajenas al problema de la pluralidad de las lenguas, representada simbólicamente por la bíblica Torre de Babel. El siglo XVI, sin embargo, tuvo que enfrentarse al problema desde perspectivas que iban más allá del debate filosófico tradicional. El descubrimiento de nuevas tierras, de nuevos lenguajes, de nuevos seres naturales sin denominación conocida, así como la proliferación de nombres para aparentemente la misma cosa, crearon un gran problema de comunicación científica precisamente en el momento en el que ésta se empezaba a erigir como uno de los valores esenciales de la investigación de la naturaleza. A la pregunta acerca de las vías óptimas para conocer la naturaleza se sumo la pregunta acerca del mejor instrumento para transmitir su conocimiento. En esta comunicación se comentan el eco que la literatura utópica de los siglos XVI y XVII se hizo de la búsqueda de este instrumento de comunicación científica, así como algunas de las propuestas procedentes de la propia práctica científica.
\end{abstract}

PALABRAS CLAVE: lenguaje, literatura utópica, Nuevo Mundo, Renacimiento, ciencia moderna

\begin{abstract}
Neither the Ancients nor the medieval philosophers were unaware of the problem of the plurality of languages, represented symbolically by the Biblical Tower of Babel. The sixteenth century, nevertheless, had to face the problem from perspectives that went beyond the traditional philosophical debate. The discovery of new territories, new languages, new natural beings without known denomination, as well as the proliferation of names for apparently the same thing, created a great problem of scientific communication precisely when this began to erect like one of the essential values of the investigation of nature. The question about how to know nature became inseparable from the question about the best instrument to transmit natural knowledge. I propose here a review about how the utopian literature of sixteenth and seventeenth centuries echoed this problem about scientific communication, as well as some of the proposals coming from the own scientific practices.
\end{abstract}

KEYWORDS: language, utopical literature, New World, Renaissance, modern science

Una de las principales imágenes de la Revolución Científica consiste en presentarla como el resultado del gran triunfo del estudio empírico de la naturaleza contra el poder de la tradición y el estudio textual. En las últimas décadas, la Historia de la Ciencia ha insistido en la centralidad de la experiencia como característica esencial de la Revolución Científica. Lo ha hecho, sin embargo, desde una perspectiva muy diferente a la adoptada por los historiadores más fielmente positivistas. Mientras que estos concebían la ciencia como una empresa puramente cognitiva, la historia contemporánea se ha esforzado en subrayar 
que el empirismo no es sólo una cuestión de pura teoría del conocimiento, sino que para entender los usos y significados que se atribuyeron a la experiencia en los siglos XVI y XVII es necesario tener también en cuenta las prácticas mediante las cuales se elabora el estudio empírico, sus formas de transmisión, sus estrategias para dotarlo de credibilidad, etc. Ha quedado ya demostrado que la defensa del estudio empírico de la naturaleza fue un proceso mucho más complejo que un mero «abandonemos los libros y volvamos la mirada a las cosas mismas». Las nuevas formas de experiencia requirieron nuevas prácticas de exploración de la naturaleza, pero también requirieron nuevas formas de transmisión y circulación del conocimiento.

Me quiero referir aquí a un instrumento científico fundamental en tanto que es absolutamente necesario para el desarrollo del conocimiento científico. Un instrumento sin tornillos, sin vidrios. Un instrumento cuyas piezas son letras o fonemas y cuya aparente ligereza enmascara las más graves tradiciones o consecuencias: el lenguaje.

¿Un hecho es un hecho si no es transmitido? Quizá sí, seguramente sí, a menos claro está, que hagamos de la existencia del mundo un simple derivado de nuestros órganos de percepción o una creación de la mente humana, especulación que siempre ha tentado a los filósofos. Pero un hecho no es lo mismo que un hecho científico, cosa que con demasiada frecuencia parecen olvidar quienes se enfrascan en los debates sobre el realismo científico. El conjunto de los hechos reales no coincide con el conjunto de los hechos científicos, es más, hay muchos hechos científicos que a lo largo de la historia han pasado de la existencia a la inexistencia, o viceversa; del mismo modo que hay hechos del mundo que no tienen porqué formar parte de la ciencia. De todos los hechos del mundo, los hechos científicos tienen ciertas características, tienen una vida, nacen y mueren y dependen, como cualquier otra creación cultural, de los momentos históricos e intelectuales ${ }^{1}$. Pero de todas las características de los hechos científicos, una siempre les acompaña: la necesidad de que sean transmitidos. Un hecho para que sea científico ha de ser transmitido a través de instrumentos verbales, icónicos o simbólicos. No hay, por

\footnotetext{
${ }^{1}$ La distinción entre hechos y hechos científicos ha sido subrayada de una forma interesante por Lorraine Daston y los autores de los ensayos agrupados por ella en el volumen DASTON, L. (Ed.), Biographies of Scientific Objects, Chicago: University of Chicago Press, (2002). A decir verdad, la cuestión había sido ya ejemplarmente argumentada por PAOLO ROSSI en el capítulo titulado «La ciencia el olvido» de su libro El pasado, la memoria, el olvido, Buenos Aires, Nueva Visión, 2003, 155-197 (1 $1^{\mathrm{a}}$ ed. italiana de 1991); en él Paolo Rossi ofrece una excelente selección de entidades o hechos científicos que existieron en un determinado momento de la historia de la ciencia para morir después y cuya muerte no los excluye de la ciencia si consideramos que ésta tiene carácter histórico.
} 
tanto, ciencia sin lenguaje. Toda reflexión acerca del conocimiento científico requiere, o al menos presupone, una determinada concepción de la naturaleza del lenguaje. Así lo percibieron ya Platón, Aristóteles, Epicuro o Lucrecio. A partir de ellos, y durante siglos, el debate sobre el lenguaje -como también el debate sobre el conocimiento científico- se movió en un terreno profunda y casi exclusivamente especulativo.

Aunque la cuestión es mucho más compleja, se puede decir que las tres tesis en liza eran:

1. El hombre impone nombres a las cosas según su voluntad pero de modo completamente arbitrario. Por tanto ni siquiera se plantea el problema de la congruencia entre las palabras y las cosas.

2. Existe una congruencia entre las palabras y las cosas, pero esta congruencia deriva de la razón y del entendimiento de la naturaleza que posee el hombre, el nomenclátor.

3. Entre palabras y cosas existe una absoluta y natural congruencia. Las palabras son espejos fieles de las cosas y las cosas llevan en sí la marca de la palabra ${ }^{2}$.

La segunda tesis había sido defendida por Aristóteles, la tercera por Platón ${ }^{3}$. Los escolásticos, como en tantas otras cuestiones, intentaron conciliar a Aristóteles con el

${ }^{2}$ La filosofía del lenguaje contemporánea tiende a olvidar, o a no tomar en consideración, su historia más allá en el tiempo del pensamiento de John Locke y a reducir el debate al conflicto entre naturalismo y convencionalismo. Los trabajos de algunos historiadores ponen de manifiesto la pobreza de esta perspectiva y la inmensa complejidad de las concepciones del lenguaje en la Antigüedad clásica y el pensamiento medieval. Me remito aquí los excelentes trabajos de FORMIGARI, L. (1970), Linguistica ed empirismo nel Seicento inglese, Bari: Laterza; FORMIGARI, L. (2001), Il linguaggio. Storia delle teorie, Roma-Bari, Laterza; Demonet, M. L. (1992), Les Voix du Signe. Nature et origine du langage à la Renaissance (1480-1580), París: Champion-Slatkine.

3 Aristóteles expone su teoría del lenguaje principalmente en el De interpretatione, donde afirma que «El nombre es un sonido vocal significativo por convención», que expresa las afecciones del alma y las imágenes de las cosas reales que se forman en la mente. Hay que subrayar, sin embargo, que si bien la relación del nombre con la imagen mental es convencional, la relación de la imagen con las cosas reales es natural y universal, la misma para todos los seres humanos, de modo que el problema que se plantea es dar el nombre justo a cada uno de los conceptos universales, lo cual tendrá importantes consecuencias en el desarrollo de las teorías lingüísticas en el siglo XVII. La interpretación naturalista de la filosofía platónica del lenguaje ha sido muy debatida y son numerosos los casos en los que encontramos a Platón caracterizado como defensor del convencionalismo. Ello se debe fundamentalmente a que en el diálogo Cratilo, donde Paltón expone su filosofía del lenguaje, solo es Cratilo el que sostiene la tesis naturalista radical, mientras que Sócrates se muestra escéptico ante ella. La bibliografía al respecto es muy abundante, por lo que me remito solamente a BARNEY, R. (2001), Names and Nature in Plato's Cratylus, Nueva 
cristianismo. Hicieron una lectura del Génesis según la cual Dios dio a Adán el poder de conocer la auténtica naturaleza de las cosas y a partir de ese conocimiento Adán impuso a las cosas un lenguaje humano pero perfectamente acorde con la naturaleza de las cosas ${ }^{4}$. La caída adánica supuso la pérdida del poder de conocer perfectamente la naturaleza, y por tanto el poder de nombrarla adecuadamente, especularmente. El episodio bíblico de la Torre de Babel no hizo sino agravar el problema y dar origen al dramático problema de la confusión de las lenguas. El renacimiento de las filosofías neoplatónicas y herméticas en los siglos XVI y XVII hizo una apuesta diferente: conciliar el Génesis con Platón y con su filosofía naturalista del lenguaje expuesta en el Cratilo. En la lectura resultante del Génesis, Dios dio a Adán un lenguaje perfecto que correspondía perfectamente a la naturaleza de las cosas. En el Paraíso adánico, el lenguaje era un espejo fiel de la naturaleza. El pecado adánico rompió aquel espejo y con su quiebra comenzó la decadencia y corrupción del conocimiento primigenio. Al tiempo que se abría una era de lenguajes convencionales alejados del primigenio lenguaje natural ${ }^{5}$.

En ambas interpretaciones, la aristotélica y la platónica, el Paraíso bíblico había sido el lugar de la perfecta armonía entre el lenguaje y el conocimiento de la naturaleza. Místicos, filólogos y humanistas se lanzaron en el siglo XVI a la caza de aquella sabiduría perdida que muchos creyeron encontrar en el estudio de las lenguas antiguas, especialmente el hebreo. Mas el siglo XVI trajo también consigo una compleja red de circunstancias que hicieron que el debate sobre la naturaleza del lenguaje tuviese que enfrentarse a nuevos problemas y salir de su ámbito puramente teórico y especulativo. Más allá de la cuestión sobre el origen de las lenguas, de la relación ontológica entre palabras y cosas, el siglo XVI tuvo que hacer frente a una realidad: el lenguaje, fuese cual

\footnotetext{
York/Londres, Routledge, y al estudio bibliográfico realizado por VAN BERKEL, T. y STOLWIJK, J. (2008), A Bibliography on Plato's Cratylus, Universidad de Leyden, recurso electrónico: media.leidenuniv.nl/legacy/Bibliography_Cratylus_July_2008.pdf.

${ }^{4}$ Esta interpretación fue defendida fundamentalmente por Tomás de Aquino en su Suma Teológica, I, Cuestion 84 y 95. Fueron fundamentales en el desarrollo de esta interpretación las tesis de los llamados «modistas» (así denominados porque se basaban en el De modus significandi de Boecio), según las cuales existían unos universales lingüísticos, unas reglas subyacentes a la formación de todas las lenguas naturales que constituirían una especie de gramática universal que garantizaba la especularidad entre el lenguaje, el pensamiento y la naturaleza de las cosas. Las palabras concretas eran convencionales, no así las formae locutiones, que corresponden a la auténtica naturaleza de las cosas y derivan del conocimiento de origen sensible. Según Boecio, fue precisamente esta forma locutiones, y no las palabras, lo que Dios dio a Adán.

${ }^{5}$ Véase BONO, J. J. (1995), The Word of God and the languages of man. Interpreting Nature in Early Modern Science and Medicine, Madison, Wisconsin, Madison University Press; HARRISON, P. (2007), The Fall of Man and the Foundations of Science, Cambridge, Cambridge University Press, cap. 1.
} 
fuese su origen, fuese natural o convencional, era un instrumento de comunicación científica. Un instrumento que cada vez mostraba más sus imperfecciones e impedía el éxito de la comunicación de informaciones, de la circulación de ideas y de la crítica inherente al conocimiento científico.

El creciente uso de las lenguas vernáculas como instrumento de comunicación científica, lejos de facilitar la comunicación científica, en muchos casos la dificultó, especialmente cuando se trataba de la transmisión de conocimiento empírico. Aparecieron graves problemas de traducibilidad en un momento en el que los diccionarios de lenguas vernáculas solo estaban naciendo. El creciente interés por la inspección ocular de la naturaleza desembocó en el descubrimiento de cosas para las que no existía nombre conocido. Cosas sin nombre. En otros casos la pluralidad de denominaciones para una misma cosa llevó a pensar que se trataba de cosas diferentes. A ello hay que sumar, entre otras cosas, el descubrimiento de nuevas lenguas como resultado de los descubrimientos geográficos.

El descubrimiento y exploración de nuevas tierras llevado a cabo fundamentalmente por españoles y portugueses desempeñó un papel fundamental en el desarrollo de las relaciones entre lenguaje y ciencia en los siglos XVI y XVII. Por un lado, el descubrimiento de la naturaleza americana supuso enfrentarse a cosas nunca vistas anteriormente, a cosas sin nombre. Las soluciones para intentar esquivar el problema fueron variadas: pintarlas, describirlas basándose en la analogía con lo ya conocido y nombrado, adoptar la terminología indígena ${ }^{6}$. Pero todas las soluciones propuestas se convertían rápidamente en fuente de problemas. Mientras humanistas y filólogos intentaban recuperar la auténtica sabiduría contenida en las lenguas antiguas para acercarse al auténtico conocimiento de la naturaleza, los viajeros y exploradores de la naturaleza parecían alejarse cada vez más de aquella perfecta relación mimética entre las palabras y las cosas.

Sin embargo, también es cierto que, por otro lado, las nuevas tierras descubiertas se convirtieron en semilla de las utopías lingüísticas de los siglos XVI y XVII ${ }^{7}$. Las

\footnotetext{
${ }^{6}$ Por lo que se refiere a la ilustración pictórica como medio de transmisión de conocimientos empíricos y los problemas a que se tuvo que enfrentar, véase GÓMEZ LÓPEZ, S. (2009), La ilustración científica y el engaño de los sentidos, en Casanueva, M. (Ed.), El giro pictórico, México, Anthropos, 39-71.

${ }^{7}$ Sobre la identificación de las nuevas tierras americanas con el paraíso biblíco y los desarrollos utópicos de esta asociación, véase CANTÚ, F. (2002), América y Utopía en el siglo XVI, Cuadernos de Historia Moderna
} 
relaciones entre lenguaje, conocimiento científico y descubrimientos geográficos adquirieron curiosas e interesantes formas en aquel periodo. Las opciones tomadas estuvieron, en la mayoría de los casos, muy lejos de decantarse por una clara apuesta por la observación libre del peso de las palabras o por los textos indiferentes al peso de la experiencia.

En 1580 Petrus Albinus (originalmente Peter Weiss pero también conocido como Petrus Albinus Nivemonti, 1543-1598), historiador de la corte de Sajonia, escribió un Commentatio de linguis peregrinis atque insulis ignotis que constituye uno de los mejores testimonios de la íntima relación entre defensa del empirismo, nuevos descubrimientos geográficos y lenguaje ${ }^{8}$. Albinus era un gran defensor de los estudios descriptivos, del necesario y detallado estudio empírico de todas las cosas, ya perteneciesen a la historia natural o civil. Era también un estudioso de las artes prácticas, especialmente de la minería y la metalurgia9. En su Commentatio, Albinus afirmaba que el descubrimiento de las nuevas tierras americanas y de las nuevas lenguas que allí se hablaban era la mejor confirmación de que sólo el estudio empírico de la naturaleza (y las lenguas eran parte de ella) podían liberar a la humanidad del largo confinamiento intelectual en el que había permanecido durante largos siglos. Lo sorprendente es el resultado que Albinus esperaba de aquel estudio experimental: no un conocimiento auténticamente nuevo; no un rechazo o marginación de las fuentes textuales para volver la mirada a las cosas mismas, sino el redescubrimiento, gracias al examen detallado de las nuevas tierras y a su cuidadosa

\footnotetext{
Anejos, I, 45-64. Los estudios sobre la literatura y el pensamiento utópicos son muy numerosos y no tendría sentido pretender recordar aquí todos ellos; me remito por tanto a una de las bibliografías más recientes, la incluida en el Cambridge Companion to Utopian Literature, edición de G. Claeys, Cambridge, Cambridge University Press, 2010.

8. Commentatio de linguis peregrinis atque insulis ignotis. Ex scripto mano ipsius exarato edidit M Samuel Cnautbius, Wittenberg, 1580. El libro, que apareció con un largo prefacio de Hugo Grotius sobre el origen de las gentes americanas, es extremadamente raro y no he conseguido ver ningún ejemplar de esta primera edición, que se volvió a publicar en 1714 y de la cual existe una traducción inglesa con la siguiente referencia: HUGO GROTIUS, EDMUND GOLDSMID y PETRUS AlBINUS (1884), On the origin of the native races of America. A dissertation by Hugo Grotius. To which is added a Treatise on foreign languages and unknown islands. By Peter Albinus. Edición y traducción del latin de Edmund Goldsmid, Londres, Unwin Bros printers. Sobre Albinus, véase BACHMAnN, M., (2000), Petrus Albinus Begründer der erzgebirgischen Geschichtsschreibung, en Kleine Chronile großer Meister - Eragebirger, auf die wir stolz sind, Vol. 1, Druckerei und Verlag Mike Rockstroh, 85-87; SAuer, B. (1953), Albinus Petrus, en Neue Deutsche Biographie, Band 1, Duncker \& Humblot, Berlín, 151. Véase también PAXMAN, D. B. (1998), Voyage into Language. Space and the Linguistic Encounter, 1500-1800, Aldershot, Ashgate Publisshing Co., 23 y ss.

${ }_{9}$ Es muy significativo para el tema que nos ocupa el hecho de que Albinus elaborase un «Lexicon metallicum» tomado de las obras de Agrícola y otros autores, manuscrito que se conserva en la Sächsische Landesbibliothek de Dresde, R101, Katalog III, 324
} 
interpretación, del auténtico conocimiento del mundo anunciado en algunos textos de la Antigüedad, especialmente en los textos bíblicos. Para Albinus la comprensión de las lenguas hasta entonces desconocidas y el examen de las nuevas tierras americanas eran la realización de una profecía y el signo de la próxima llegada de una nueva era.

En la línea de Erasmo, al que elogiaba desde las primeras líneas de su Commentatio, Albinus consideraba que todas las lenguas, por diferentes que se hubiesen hecho entre sí tras el episodio de la Torre de Babel, conservaban en ellas la marca de Dios. Su estudio era, por tanto, una forma de recuperación de la verdad. Paralelamente, el desarrollo de la geografía que había permitido a Colón y sus navegantes descubrir el Nuevo Mundo, había abierto el camino para el redescubrimiento de un mundo que ya algunas antiguas autoridades conocían. Los estudios medievales sobre el lenguaje y la naturaleza, pensaba Albinus, eran ricos en explicaciones, pero débiles en detalles. El elemento explicativo se había basado excesivamente en la racionalización y la generalización, dejando de lado la observación de los particulares. Así, por ejemplo, los medievales habían construido excelentes relatos de las setenta y dos lenguas postbabélicas, las habían asociado o identificado con lugares de la geografía conocida y con las tribus del mundo conocido, acudiendo en la mayoría de los casos a complejísimas redes interpretativas de carácter simbólico. El descubrimiento del Nuevo Mundo y de sus lenguas ponía de manifiesto, gracias al estudio empírico, los errores de aquellas reconstrucciones textuales y simbólicas y contribuía a reconocer que la sabiduría de los signos y los números no era suficiente para desvelar los secretos de la naturaleza. Se imponía recoger, coleccionar y analizar la mayor información posible sobre la geografía, los fenómenos naturales y las lenguas. El estudio empírico de las nuevas tierras y las nuevas lenguas llevaría a la correcta interpretación de los antiguos, tanto paganos como cristianos.

Si toda una corriente de intelectuales del siglo XVI había estado inspirada por la esperanza de encontrar el auténtico conocimiento del mundo en los textos de la más remota Antigüedad, también hubo, como Albinus, quien consideró que aquella vieja verdad había de ser buscada en los nuevos descubrimientos derivados de la experiencia. El uso de las analogías para describir lo nunca antes observado ni nombrado fue una constante en la descripción de las extrañas maravillas americanas. El Viejo Mundo fue incorporado al Nuevo Mundo, haciendo de las novedades americanas simples variantes de 
la naturaleza conocida ${ }^{10}$. El siglo XVI no estaba aún preparado para reconocer lo radicalmente diferente como algo nuevo. El humanista español Hernán Pérez de Oliva (1494?-1531) decía que los viajes de Colón habían tenido la finalidad de «mezclar el mundo y dar a aquellas tierras extrañas la forma de la nuestra» ${ }^{11}$. Richar Hakluyt (1552/53?-1616), corresponsal de Abraham Ortelio (1527-1598) y Gerad Mercator (15121594) y autor de los Divers voyages touching the discovery of America and the islands adjacent (1582), pensaba que los nuevos descubrimientos geográficos llevados a cabo por los ingleses eran los anunciados por el profeta en el Salmo 107 de la Biblia: «Se hicieron a la mar en sus barcos; para comerciar surcaron las muchas aguas. Allí, en las aguas profundas vieron las obras del Señor y sus maravillas» (versículos 23-24). Hablando de las islas cercanas a Frislandia, Hakluyt describía sus inmensas riquezas, las artes y conocimientos de sus habitantes, subrayando que si bien era probable que en su día hubiesen conocido el latín, ya no lo entendían, pues «they have a peculiar language, and letters, or caracters, to themselves» ${ }^{12}$.

Mas en ese proceso de incorporación, de apropiación, se proyectaron también en el Nuevo Mundo los patrones del desarrollo histórico del Viejo Mundo. Casi desde los primeros viajes de exploración, muchos percibieron el descubrimiento del Nuevo Mundo como el redescubrimiento y recuperación de aquella perdida Edad Aurea en la que el hombre había habitado en el Paraíso. En toda la tradición cristiana, la descripción del Paraíso relatada en el Génesis resaltaba la relación entre lenguaje, conocimiento y poder. Dios había dado a Adán un lenguaje perfecto, un lenguaje cuyas palabras coincidían con la naturaleza de las cosas. Un lenguaje especular, sin equívocos, un lenguaje que llevaba en sí la marca de la verdad. Gracias a ese lenguaje, Adán había tenido un conocimiento perfecto de las cosas y, lo que es más importante, poseyendo un lenguaje que coincidía con la naturaleza de las cosas, también había poseído las cosas mismas. Tras el pecado

\footnotetext{
${ }^{10}$ Considero muy relevantes las reflexiones que en este sentido se hacen en GRAFTON, A. (ed.) (1995), New Worlds, Ancient Texts: The Power of Tradition and the Shock of Discovery, Harvard University Press.

${ }^{11}$ Hernán PÉREZ DE Oliva, Historia de la invención de las Indias, estudio preliminar, edición y notas de Juan José Arrom, Madrid: Siglo XXI Editores, 1991, 50.

${ }^{12} \mathrm{Cfr}$. Divers voyages touching the discovery of America and the islands adjacent, collected and published by Richard Hakluyt, Bristol, 1582, V y 82. Frislandia (también conocida como Frisland, Drischland, Friesland, Freezeland o Frixland) era una de las llamadas «islas fantasmas» que aparecen en la mayoría de los mapas y cartas náuticas del Océano Atlántico Norte realizadas entre 1560 y 1660. Es probable que Frislandia fuese el nombre dado inicialmente a Islandia, pero en 1558 Nicolò Zeno la representa en su mapa como una isla distinta.
} 
adánico, Dios decidió arrebatar al hombre el poder sobre la naturaleza y el medio empleado fue arrebatarle ese lenguaje especular que le había concedido. La asociación de las tierras americanas con el Paraíso terrestre, con la recuperación de la Edad Aurea del conocimiento, condicionó también, por tanto, la relaciones entre el lenguaje, las nuevas tierras y las maravillas y extrañezas sin nombre que en ellas se encontraban.

Las relaciones entre empirismo, concepción del lenguaje y descubrimientos geográficos quedaron especialmente patentes en la producción intelectual que se desarrolló en torno al impresor Christoph Plantin en Amberes, uno de los principales centros europeos de estudios bíblicos en el siglo XVI y cuna de la Biblia Políglota promovida por Felipe II. Núcleo también de la «Familia Charitatis» o «del Amor»-una especie de secta de ideales políticos y religiosos que aspiraba a la conciliación entre los pueblos tras las brechas abiertas por la Reforma protestante- los intelectuales del círculo de Plantin hicieron de los estudios teológicos, filosóficos y científicos los ejes de su proyecto conciliador ${ }^{13}$. Para ellos, la unión de filología y teología estuvo especialmente ligada a su convicción en la existencia de una prisca theologia o prisca sapientia ocultada y cubierta por la corrupción de los siglos y a la que se podría regresar gracias a la recreación en la Tierra de una nueva edad adánica, idea que encontró sus fuentes de inspiración en la tradición hermética y el cabalismo cristiano ${ }^{14}$. Parte fundamental de su defensa de este saber originario fueron sus reflexiones sobre el origen y naturaleza del lenguaje, entre las que destacan las de Goropio Becano (Van Gorp, 1519-1573) en su Hermathena (1580), cuyo prefacio estaba dedicado al otro gran teórico ce las lenguas del círculo de Plantin: Benito Arias Montano, director de la Biblia Políglota de Amberes ${ }^{15}$. Las ideas sobre el lenguaje defendidas por este grupo -que tenían en el pensamiento de Guillaume Postel (1510-1581) un claro referente- estuvieron íntimamente ligadas al estudio de la historia y

\footnotetext{
${ }^{13}$ Sobre los Familia Charitatis, también conocida como Family of Love por el gran peso que tuvo en la Inglaterra de la primera mitad del siglo XVII, véase HAMILTON, A. (1987), The Family of Love, Cambridge, Lutterworth Press; Williams, G. H., (1962), Spiritualism and Rigorism among the Netherlanders and Lower Germans, en The Radical Reformation, Filadelfia, The Westminster Press, cap. 19; MARSH, CH. W. (1994), The Family of Love in English Society, 1550-1630, Cambridge, Cambridge University Press.

${ }^{14}$ Sobre los intereses y herencia cabalista de este grupo véase WILKINSON, R. J. (2007), The Kabbalistic Scholars of the Antwerp Polyglot Bible, Leyden: Brill.

15 Goropio BeCANO (Van Gorp), Opera hactenus in lucem non edita, nempe Hermathena, Hieroglyphica, Vertumnus, Gallica, Francica, Hispanica, Amberes, Imp. Plantin, 1580. Las principales reflexiones de Arias Montano sobre el lenguaje se encuentran en su Liber Joseph sive De arcano sermone, Amberes, 1583. Un excelente estudio y traducción de este texto se encuentra en internet en la página personal de Víctor Manuel Bermúdez Bermejo: http://www.viejoynuevo.com/arias-montano.
} 
la filosofía natural y determinaron desde sus metodologías de estudio de la naturaleza hasta los valores y significados atribuidos a los resultados de sus trabajos naturalistas. Formaron parte del círculo de Plantin nombres tan relevantes para la ciencia de la época como los ya nombrados Abraham Ortelio y Gerard Mercator, pero también Rembert Dodoens, Mathias de L'Obel (Lobelius), Charles L’Ecluse (Clusius), para quienes la sabiduría contenida en los textos bíblicos, las concepciones acerca de la naturaleza y origen del lenguaje y la investigación de la naturaleza corrieron de forma paralela y equilibrada en su investigaciones naturalistas ${ }^{16}$. Lejos de apostar por una investigación puramente filológica de la historia y la filosofía natural, los intelectuales del círculo de Plantin defendieron un estudio empírico y detallado de la naturaleza. Reacios a aceptar las imposiciones ideológicas e interpretativas de los teólogos de la época, los familistas -y afines- del círculo de Plantin optaron por una búsqueda de las verdades filológicas y científicas que se apartaba de dogmas e imposiciones teológicas para seguir el camino de la investigación de la naturaleza, la astronomía, la geografía, la historia natural y la cosmología, estudios éstos que para ellos adquirieron un valor providencial en cuanto huellas que, correctamente interpretadas, podrían llevar a una recuperación del auténtico y primigenio conocimiento. La convertibilidad de los dos libros -el de la naturaleza y el de las Sagradas Escrituras- autorizaba la utilización de la observación de la naturaleza y del estudio de textos científicos para explicar las ambigüedades y aparentes contradicciones de las Sagradas Escrituras.

Las relaciones entre lenguaje e investigación de la naturaleza quedaron especialmente plasmadas en la Naturae Historia de Benito Arias Montano (1601) ${ }^{17}$. A lo largo de toda su vida, Arias Montano había dedicado grandes esfuerzos a promover el intercambio de información sobre plantas, remedios naturales y semillas procedentes tanto del Viejo como del Nuevo Mundo, conocía bien las novedades y controversias filosóficas y científicas de su época y estaba en contacto con los más importantes naturalistas de su tiempo, compartiendo con ellos la defensa del estudio empírico de la

\footnotetext{
${ }^{16}$ Esta intersección de elementos teológicos y religioso, tradiciones intelectuales y formas de investigación de la naturaleza está reflejada en el estudio sobre Ortelio de MANGANI, G. (2006), Il «mondo» di Abramo Ortelio. Misticismo, geografía e collezionismo nel Rinascimento dei Paesi Bassi, Ferrara, Franco Cosimo Panini Editore.

${ }^{17}$ Una estupenda edición contemporánea de esta obra de Arias Montano fue publicada en 2002 como Historia de la Naturaleza. Primera parte del Cuerpo de la Obra Magna, edición de F. Navaro Antolín, Huelva, Servicio de Publicaciones de la Universidad de Huelva.
} 
naturaleza y la valoración de los beneficios prácticos que de él se derivaban ${ }^{18}$. Sorprendentemente, al final de su vida Arias Montano escribió una Naturae Historia en la que expresaba su convicción de que todo posible saber estaba ya contenido en las Sagradas Escrituras, que la naturaleza era solo una metáfora de la Biblia y que, por tanto, para estudiar y comprender los secretos de la naturaleza era mejor estudiar filológicamente los textos sagrados que estudiar directa y empíricamente las cosas mismas. En la naturaleza, pensaba Arias Montano, nada hay realmente nuevo, y si en alguna ocasión algo nos lo parece, solo es cuestión de leer atentamente las palabras bíblicas para comprender que realmente nuevo no es. Hacer filología era, para Arias Montano, lo mismo que estudiar la naturaleza misma, pues en la palabra de Dios se encontraba la naturaleza de las cosas. Su obsesión por las concordancias bíblicas le hizo estar convencido, por ejemplo, de que las minas de Perú correspondían al fabuloso Ofir de la Antigüedad bíblica, la mina del rey Salomón, y que éstas habían permanecido ocultas durante siglos por deseo divino para que las encontrase Felipe II, el nuevo Salomón. Las piedras preciosas que Arias Montano poseía en su colección de objetos naturales y artificiales habían sido elegidas por sus simbolismos bíblicos: allí estaban las descritas para las vestiduras del sumo sacerdote en el Exodo (28, 17 y ss); las que adornaban los muros de la Jerusalén celeste, que a su vez correspondían a las doce piedras zodiacales y a los doce apóstoles. Buscó incansablemente, durante 15 años, plantas que pudiesen corresponder al arbusto del que se habla en el Eclesiástico, 24 -uno de los textos bíblicos sapienciales; intentó conseguirlo en España e Italia y durante algún tiempo pensó que se podía encontrar en las Indias occidentales ${ }^{19}$.

José de Acosta, en su Historia natural y moral de las Indias occidentales y orientales (1590), fue especialmente reacio a admitir estas concordancias bíblicas y proféticas sobre el Nuevo Mundo, así como la posibilidad de que los antiguos hubiesen viajado a América. Admitía, sin embargo, que la Atlántida de que hablaba Platón en su Critias no podía ser sino América. Y recordaba cómo el sabio Séneca, en su tragedia Medea, había previsto el descubrimiento de las Indias Occidentales:

\footnotetext{
${ }^{18}$ En los últimos años se han realizado importantes estudios sobre Benito Arias Montano. Me remito a la completa bibliografía recogida por CASO AMADOR, R. (2004-2005), Bibliografía sobre el Humanista Benito Arias Montano (1832-2005), Etiópicas. Revista de Letras Renacentistas, 1, 271-310.

19 Véase GÓMEZ LÓPEZ, S. (2007), Lucifera y fructifera: ciencia y utilidad en las colecciones naturalistas de la España de los Austrias, en EAmON, W. y NAVARro, V., (Eds.), Más alla de la Leyenda Negra. España y la Revolución Cientifica, Valencia, Publicaciones de la Universidad de Valencia, 155-180.
} 
«Tras largos años vendrá / Un siglo nuevo y dichoso / Que al Océano anchuroso /Sus límites pasará /Descubrirán grande Tierra /Verán otro Nuevo Mundo / Navegando el gran profundo / Que ahora el paso nos cierra» ${ }^{20}$.

Toda utopía va encaminada a proyectar y describir estados de cosas en los que los grandes problemas que atenazan a la sociedad y la cultura real queden eliminados. Una clara muestra de la crisis del lenguaje como instrumento de transmisión de ideas, saberes e información empírica en los siglos XVI y XVII es la relevancia que la literatura utópica de la época le prestó ${ }^{21}$. La búsqueda de un lenguaje perfecto era parte de la búsqueda de una sociedad y una cultura perfectas, una búsqueda de un estado utópico que fue representada por el hombre navegante que viaja a mundos desconocidos y encuentra en ellos estados paradisíacos, sociedades perfectas o admirables, ya sea por su organización moral, política o intelectual. Tomás Moro comenzaba su famosa Utopía contando un viaje de navegación por los océanos, la Nueva Atlántida de Francis Bacon tenían inmensas analogías con los viajes de exploración realizados por españoles y portugueses en el siglo XVI. Si los viajes de navegación oceánica se convirtieron en fuente de inspiración de la literatura utópica y las tierras recién descubiertas fueron identificadas con los paraísos utópicos, los descubrimientos celestes de finales del siglo XVI y principios del siglo XVII y las nuevas propuestas cosmológicas desencadenaron una larga serie de viajes cósmicos en los que a menudo los navegantes celestes encontraban extraños mundos habitados ${ }^{22}$. Los descubrimientos de nuevas tierras, en especial de las Indias Occidentales, se mezclaron en la imaginación de la época con los descubrimientos de nuevos astros, los viajes por los océanos en busca de nuevas tierras dispararon los sueños de viajar por los inmensos espacios celestes y en ocasiones lo que descubrieron en estos últimos no era más que la transposición de lo que habían descubierto -o habían creído descubrir- en los viajes alrededor del globo terráqueo. Así, si las tierras americanas se convirtieron en fuente de utopías, creyendo encontrar en ellas el paraíso perdido, los viajeros cósmicos encontraron

\footnotetext{
${ }^{20}$ JOSÉ DE ACOSTA, Historia naturaly moral de las Indias, Madrid, 1590, 47 y ss.

${ }^{21}$ Véase C. MARRONE (2004), Le lingue utopiche, Viterbo, Stampa Alternativa \& Graffiti.

22 Sobre este tema véase NiCOLSON, M. H. (1948), Voyages to the Moon, Nueva York, McMillan; DiCK, S. J. (1982), Plurality of Worlds. The Origins of the Extraterrestrial Life Debate from Democritus to Kant, Cambridge, Cambridge University Press; BAINE CAMPBELL, M. (1997), Impossible Voyages: Seventeenth Century Space Travel and the Impulse of Ethnography, Literature and History, vol. 6, n. 2, 1-17.
} 
en los lejanos astros habitantes y organizaciones sociales inspiradas en los relatos de los cronistas y navegantes del siglo XVI.

Dos de las más famosas utopías escritas en el siglo XVII describían viajes cósmicos a la Luna y al Sol. Eran viajes aparentemente inspirados por la nueva cosmología heliocéntrica, mas basta leerlos con atención para darse cuenta de que aquellos viajes cósmicos eran, en realidad, una transposición de los viajes transatlánticos y que lo descubierto en los lejanos astros correspondía a lo descubierto en las tierras americanas y el lejano Oriente y a la interpretación de éstas como el Paraíso perdido y redescubierto. En 1638 se publicó póstumamente la obra The Man in the Moon, del obispo inglés Francis Godwin (1562-1633) 23. Godwin, que probablemente había asistido a los cursos de Giordano Bruno en Oxford en 1583, era un gran defensor del copernicanismo sin grandes conocimientos astronómicos pero si con un gran interés por las novedades cosmológicas $^{24}$. Se ha supuesto alguna vez que debió leer el Somnium sive Astronomia lunaris de Kepler y que eéta habría sido la fuente de inspiración de su obra, mas lo cierto es que difícilmente lo pudo hacer, pues el texto de Kepler se publicó en 1634, un año después de la muerte de Godwin, y aunque el manuscrito circulaba ya desde 1611 no hay noticia de que llegase a Inglaterra ${ }^{25}$. Lo que no cabe duda es de que conocía bien la Dissertatio cum Nuntio Sidereo que Kepler escribió como respuesta al Sidereus Nuncius de Galileo en 1611 y donde se había explayado acerca de la posibilidad de que hubiese habitantes en la Luna, especulando incluso sobre sus características. El protagonista de la obra de Godwin era Domingo Gonsales, personaje que decía haber nacido en Sevilla en 1542 y haber estado en la Universidad de Salamanca, donde había estudiado la nueva astronomía. Relataba también que había acompañado al Duque de Alba a los Países Bajos entre 1568 y 1573, donde había conocido bien a los «malditos flamencos» que le habían robado todo lo que

\footnotetext{
${ }^{23}$ No se sabe exactamente cuándo Godwin escribió la obra, aunque lo más probable es que fuese en 1629 o después, dado que en el The Man in the Moon hacía referencia a otra obra suya publicada en 1629, el Nuncius Inanimatus, una obra en la que se desarrollaban técnicas para mandar rápidamente mensajes a distancia y que años más tarde Cromwell se tomaría muy en serio; veáse al respecto MCCOLLEY, G. (1937), The date of Godwin's Domingo Gonzales, Modern Philology, vol. 35, n. 1, 47-60; PoOLE, W. (2006), Nuncius Inanimatus. Seventeenth Century Telegraphy: The Schemes of Francis Godwin and Henry Reynolds, The Seventeenth Century, vol. 21, n. 1, 45-73

${ }_{24}$ Véase HutTon, S. (2005), The Man in the Moon and the New Astronomy: Godwin, Gilbert, Kepler, Études Épistéme, n. 7, Science(s) et Litterature, 3-14.

${ }_{25}$ Véase PoOlE, W. (2005), The origins of Francis Godwin's «The Man in the Moone», Pbiloloyical Quarterly, vol. 84, 189-210. Poole niega rotundamente que la fuente de inspiración de Godwin fuese el Somnium de Kepler y defiende, en cambio, que bien pudo basarse en algunos capítulos de la Anatomy of Melancholy de Robert Burton, publicada en 1621.
} 
habían podido. Aprovechando una referencia biográfica al año 1569, Godwin ponía en boca de Gonsales un muy irónico comentario sobre las relaciones entre españoles e ingleses:

«Este asunto acaeció en el año 1596, el mismo en el que cierto gran Conde de nuestro país volvió al hogar de las Indias Occidentales, de un modo triunfante, jactándose y enviando imprimir sus declaraciones sobre una gran victoria que había obtenido sobre los Ingleses, cerca de la Isla de los Pinos. Siendo por el contrario la verdad que no obtuvo de los Ingleses nada en absoluto, excepto palos y grandes pérdidas» ${ }^{26}$.

La analogía entre los viajes de exploración a nuevas tierras y los viajes cósmicos llegaba al punto de hacer a Gonsales narrar sus peripecias del viaje a la Luna desde su residencia en Sevilla, puerto habitual de salida de las naves hacia territorios americanos, y situar sus aventuras en el contexto de las batallas por el control de las rutas americanas y el apoyo del gobierno de Felipe II, no sin olvidarse de hacer que Pylonas, gobernante lunar, pida a Gonsales antes de su partida de la Luna que dé recuerdos de su parte a «Isabel, a quien designó con la expresión Gran Reina de Inglaterra [...] aunque la contaba yo entre los enemigos e España» ${ }^{27}$.

Ya desde las primeras páginas, Godwin anunciaba para el futuro de la humanidad una avalancha de descubrimientos, tales como «enviar mensajes en un instante a muchas millas de distancia, y de recibir respuesta de nuevo al momento» o de ver «hombres que vuelan de sitio a sitio por el aire», pero el que sobrepasaría a todos ellos sería el descubrimiento de un Nuevo Mundo lleno de maravillas y riquezas naturales: «tendréis noticias y conocimiento de un Nuevo Mundo, de los más inauditos e increíbles secretos de la naturaleza, con los que los filósofos de épocas anteriores no podían haber soñado» ${ }^{28}$. Y efectivamente, una vez llegado a la Luna, Gonsales se encontró con una naturaleza llena

\footnotetext{
${ }^{26}$ Cito por la edición española de la obra de Godwin, El hombre de la Luna, trad. de Xavier Resco, Ediciones Idea, Santa Cruz de Tenerife, 2003, 27-28. En esta ocasión Godwin se refería al ataque pirata de Francis Drake a las naves españolas capitaneadas por Alvarez de Bazán en Isla de Pinos, en la provincia de la Habana. Drake había tenido el apoyo secreto de Isabel I y esperaba que las operaciones de Drake acabasen con el monopolio español en el Pacífico. Pocos años antes, en 1588, Drake había dirigido la batalla Invencible.

${ }^{27}$ Godwin, El hombre de la Luna, 28.

28 Ibid., 28
} 
de novedades, maravillas y extrañezas cuya descripción era una especie de paráfrasis de lo contado por los cronistas de Indias. Así se expresaba Gonsales:

«toda clase de cosas allí eran de un tamaño superior en 10, 20 e incluso 30 veces al nuestro. Sus árboles eran al menos tres veces más altos que los nuestros, y muchas veces más de cinco veces la anchura. Lo mismo sus hierbas, bestias y aves; aunque de compararlas con las nuestras, no sabría bien cómo, porque no encontré nada allí, ninguna especie tanto de bestia o ave que se pareciera a las nuestras, excepto Golondrinas, Ruiseñores, Cucos, Becadas, Murciélagos, y algunas especies de pájaros silvestres, y también aves como mis Gansa [...] Pero sobre estas novedades habrá más en su debido $\operatorname{lugar»}{ }^{29}$.

Gonsales no era capaz de precisar mucho más, pues se encontraba con las mismas dificultades que habían tenido los primeros exploradores del continente americano para describir cosas absolutamente nuevas, jamás vistas con anterioridad y por tanto imposibles de describir con palabras:

«Pero si me preguntáis de qué color era aquel, debo deciros que era de un color nunca visto en nuestro mundo terrenal y, por lo tanto, no puede sernos descrito por nadie, ni ser concebido por nadie que no lo haya visto anteriormente. Así como es un asunto increíblemente difícil explicarle a un hombre ciego de nacimiento la diferencia entre el azul y el verde, no puedo imaginar ningún medio de describiros este color lunar, al no tener afinidad con color alguno que no haya visto con mis ojos» ${ }^{30}$.

Las dificultades de Gonsales para expresar con palabras lo nunca visto se unían a la dificultad para entender a los propios selenitas, que además de hacer «un uso contínuo del Tabaco», hablaban lenguajes completamente diferentes a todos los conocidos. Los guiños a la relación entre el lenguaje perfecto prelapsario del Paraíso bíblico y a la prohibición divina de aspirar a más conocimientos de los permitidos aparecían cuando Pylonas, el máximo gobernante de los selenitas, pide que se instruya a Gonsales en su lengua, pero

\footnotetext{
29 Ibid., 47.

30 Ibid., 52
} 
con la prohibición de que se le haga partícipe de determinadas materias que no debe conocer. Pylonas ordenó -contaba Gonsales- que:

«con toda diligencia se me instruyera en su lenguaje. Y por último, que bajo ningún concepto se me instruyera sobre determinadas materias por él especificadas, sin importar cuáles eran esas materias, no debía por ningún medio obtener conocimiento de ellas [...] Así que me parecía que estaba en el mismo Paraíso» ${ }^{31}$.

El lenguaje de los selenitas era un lenguaje perfecto y, en palabras de Godwin, «un asunto asombroso sobre el que reflexionar». La perfección de su lenguaje se basaba en que era absolutamente diferente a todos los conocidos por los hombres en la tierra, un lenguaje que todos compartían y con el que todos se entendían. Era un lenguaje que no estaba hecho de letras y palabras, sino de «melodías y sonidos inarticulados que ninguna letra puede expresar». En el lenguaje de los selenitas, había pocas palabras y a cada una correspondía una cosa, dificultades que tenían, sin embargo, la ventaja de hacer que todos los habitantes de cualquier región de aquel astro se entendiesen entre sí3 ${ }^{32}$. No cabe duda de que Godwin estaba pensando en la lengua de los chinos, una de las cuestiones que más interesaron a viajeros, exploradores y teóricos del lenguaje durante los siglos XVI y XVII; de hecho las peripecias del viajero Gonsales tras abandonar la Luna continúan en China, donde cae y es apresado por sus habitantes, los cuales hablan una lengua con las mismas características que la de los habitantes de la Luna ${ }^{33}$. En una época de gran proliferación de lenguas y de creciente dificultad de comunicación entre ellas, las noticias que llegaban de China sobre su lenguaje, especialmente gracias a la obra de jesuitas como Matteo Ricci, despertaron una gran admiración y la utopía de crear un lenguaje común a todos los

\footnotetext{
31 Ibid., $56-57$

32 Ibid., 59 y ss.

${ }_{33}$ Cuando de regreso a la Tierra Gonsales cae en China y es apresado por sus habitantes, sólo se puede entender con ellos por signos, hasta que pasado un tiempo va aprendiendo su idioma; así lo expresa Godwin: «No podía entender su lenguaje de ninguna manera [...] Pero con el tiempo [...] aprendí la lengua común de aquella Provincia (porque casi todas las provincias en China tienen su propia lengua) [...] El me respondió en una lengua diferente (que todos los Mandarines, como aprendí posteriormente, usan) y que, como la de los Lunares consistían en gran parte en melodías», Ibid., 10. Sobre esta cuestión véase KnOwLSON, J. R. (1968), 'Man in the Moone'. The East Indies Trade Route and a 'Language' of Musical Notes, en Modern Philology, vol. 65, n. 4, 357-361.
} 
hombres ${ }^{34}$. Así lo recordaba el también jesuita José de Acosta en su Historia natural y moral de las Indias, donde subrayaba las ventajas de que los signos escritos no se refiriesen a palabras, sino a las propias $\operatorname{cosas}^{35}$. El viaje a la Luna narrado por Godwin tenía más similitudes con las descripciones de José de Acosta que con el Somnium de Kepler, y si bien aparecían algunas defensas copernicanas y algunas alusiones a los nuevos descubrimientos astronómicos -como por ejemplo a las manchas solares- lo que prevalecía eran las descripciones y reflexiones propias de misioneros y cronistas de Indias. No sería de extrañar que la obra de Acosta hubiese sido la fuente de información de Godwin para elaborar su viaje fantástico, pues había sido traducida y publicada en inglés en 160436 .

Godwin, a través de su personaje Domingo Gonsales, reflejaba así los grandes problemas de comunicación a los que se enfrentaron los hombres del siglo XVI, y en especial aquellos que viajaron a las nuevas tierras. Pero aprovechaba también para aludir a la necesaria búsqueda de un lenguaje perfecto como el que existió un tiempo en el Paraíso adánico, y lo cierto es que tanto el lenguaje de los chinos como el que hablaban los habitantes de la Luna le hacían creerse en aquel Paraíso. No pienso que Godwin creyese en la posibilidad de una recuperación del lenguaje especular del Paraíso, pero éste si podía ser interpretado como modelo o ideal regulativo al que aspirar:

«discerní la posibilidad de crear un lenguaje (y de fácil aprendizaje) tan rico en expresión como cualquier otra lengua del mundo, consistente en melodías solamente, del cual mis amigos podrán saber más si así lo desean. Es un gran misterio y de más valía una vez obtenido de lo que a primera vista podríais imaginar» ${ }^{37}$.

La existencia de un lenguaje sin ambigüedades, sin equívocos, un lenguaje que fuese un espejo de la naturaleza, fue durante buena parte del siglo XVI interpretado como el lenguaje del Paraíso al que había que volver si se quería recuperar el auténtico conocimiento del mundo. El perfeccionamiento del saber pasaba por una recuperación

\footnotetext{
34 Sobre Matteo Ricci véase JonAthan SPENCE, D. (2002), El palacio de la memoria de Mateo Ricci: un jesuita en la China del siglo XVI, Barcelona, Tusquets; CROnIN, V. (2000), The Wise Man from the West: Matteo Ricci and his Mission to China, Londres: Harvill Press.

35 Op. cit. 403-405.

36 The Naturall and Morall Hitorie of the East and West Indies by Joseph Acosta, Londres, 1604

${ }^{37}$ El hombre de la Luna, cit., 60
} 
del lenguaje más antiguo posible. El siglo XVII mantuvo la idea de un lenguaje perfecto como el existente en el Paraíso bíblico, pero dejó de creer que el objetivo era volver a él para empezar, en cambio, a interpretarlo como un ideal regulativo al que había que llegar gracias a la paciente y metódica investigación de la naturaleza ${ }^{38}$. Así lo interpretó Francis Bacon y así lo haría uno de los principales proyectores de lenguajes artificiales del siglo XVII, John Wilkins, que retomó muchas de las ideas de Godwin en su The Discovery of a New World or a Discourse tending to Prove that it is Probable that they May Be a Habitable World in the Moon (1640). ${ }^{39}$

En 1649, el también copernicano Cyrano de Bergerac (1619-1655) escribió una obra estrechamente emparentada con la de Godwin: El Otro Mundo: los estados e imperios de la Luna ${ }^{40}$. Aunque muy amigo del católico Gassendi y admirador de su filosofía, Cyrano formaba parte de la corriente de pensamiento libertino que por aquella época tanto flirteaba con el ateísmo en Francia. Especialmente crítico con el antropocentrismo católico, la nueva cosmología copernicana que exiliaba al hombre de su lugar privilegiado en el universo parecía ser la confirmación física de sus actitudes ante la moral y la religión. Los paralelismos entre la obra de Godwin y la de Cyrano no nos pueden hacer olvidar sus grandes diferencias de fondo y nos ayudan a interpretar en claves muy diferentes lo que en apariencia son similares viajes a la Luna. Si Godwin había subrayado las analogías entre aquella Luna y un Paraíso bíblico que tanto se parecía a América, Cyrano es aún más explícito en la descripción de aquel otro Mundo como el Paraíso bíblico. A decir verdad, en la Luna se encuentra el auténtico Paraíso mal llamado terrenal que los hombres creían perdido. Ya para empezar, cuando el protagonista cae sobre la superficie lunar se estrella sobre un árbol de manzanas que le embadurnan el cuerpo:

\footnotetext{
38 Véase FORMIGARI, L., Linguistica ed empirismo nel Seicento inglese, cit., 9-28; STILLMAN, R. E. (1995), The new philosophy and universal languages in seventeenth-century England: Bacon, Hobbes, and Wilkins, Londres, Bucknell University Press, 1995; MAAT, J., (2004), Philosophical Languages in the Seventeenth Century: Dalgarno, Wilkins, Leibniz, Dordrecht, Kluwer.

$39 \mathrm{~J}$. Wilkins también retomará las ideas de Godwin en su Mercury: or the Secret and Swift Messenger (1641), véase C. MARRRONE, Le lingue utopiche, op. cit, 99-100.

${ }^{40} \mathrm{La}$ obra fue escrita por Cyrano en 1650 y publicada póstuma en 1657 con el título Histoire comiqué des Estats et empires de la Lune. Existe una buena edición contemporánea en las Euvres completes de Cyrano de Bergerac, edición de M. Alcover, París, Honoré Champion, 2000, pero en este artículo se seguirá la edición española titulada El otro Mundo o los Estados e Imperios de la Luna, traducción, notas y apéndice de Pollux Hernúñez, Madrid, Anaya, 1987. Sobre Cyrano de Bergerac, veánse los siguientes estudios: AlCOVER, M. (1970), La Pensée philosophique et scientifique de Cyrano de Bergerac, París-Ginevra, Droz; HARTH, E. (1970), Cyrano de Bergerac and the Polemics of Modernity, Nueva York, Columbia University Press; Cardoze, M. (1994), Cyrano de Bergerac: libertin libertaire, París, Lattès; TORERO-IBAD, A., (2009), Libertinage, science et philosophie dans le matérialisme de Cyrano de Bergerac, París, Honoré Champion.
} 
«Después de caer durante largo tiempo, según colijo (pues la rapidez del descenso debió de impedirme notarlo), lo más lejano que acierto a recordar es que me hallé bajo un árbol, enredado entre tres o cuatro ramas bastante gruesas que había tronchado en mi caída, y la cara mojada con una manzana contra la que me estrellé. Por suerte, aquel lugar era, como pronto lo sabréis, el paraíso terrenal, y el árbol sobre el que caí era precisamente el Árbol de la Vida» ${ }^{41}$.

En efecto, un joven lunariano pronto explica al viajero cósmico que ese lugar es el Paraíso en el que habían vivido Adán y Eva, los cuales, expulsados tras su pecado, se exiliaron a la Tierra, tras lo cual ningún sacerdote de la Luna evocaba a Adán sin que el recuerdo de «aquella perfecta filosofía» le hiciese suspirar:

«Esta tierra es la luna que veis desde vuestra esfera y este lugar que pisáis es el paraíso terrestre, en el que jamás entraron más de seis personas: Adán, Eva, Enoch, yo, que soy el viejo Elías, san Juan Evangelista y vos. Bien sabéis cómo los dos primeros fueron expulsados, pero ignoráis cómo llegaron a vuestro mundo. Sabed, pues, que tras haber gustado ambos de la manzana prohibida, Adán, que temía que Dios, irritado por su presencia, acrecentara su castigo, consideró la luna, vuestra tierra, como el único refugio donde podía ponerse a cubierto de las pesquisas de su creadon ${ }^{42}$.

En este caso, la descripción que hacía Cyrano de la Luna como el paraíso adánico era profundamente irónica. Cyrano estaba muy lejos de aceptar la interpretación cristianoplatónica del origen del lenguaje según la cual Dios había dado al hombre un lenguaje de palabras que reflejaban especularmente la esencia de las cosas. La idea de Cyrano recogía, en cambio, la interpretación del origen y desarrollo del lenguaje formulada por Gassendi, con quien había estudiado y compartido ideas y amistad, que a su vez se inspiraba en la tesis epicúreo lucreciana. Según esta tesis, había existido una primera fase en la que los hombres emitían de forma natural sonidos espontáneos que expresaban las pasiones del alma, lo cual permitía que todos se pudiesen entender entre sí; superada esa fase, los hombres habían empezado a imponer nombres a las cosas de forma convencional y por

\footnotetext{
${ }^{41}$ Cyrano de Bergerac, El otro Mundo o los Estados e Imperios de la Luna, 29.

42 Ibid., 33.
} 
tanto a expresarse en lenguas que no siempre eran conformes a su pensamiento ${ }^{43}$. El resultado había sido una corrupción del conocimiento de la naturaleza. Cyrano expresaba su desacuerdo con la idea de un lenguaje originario y perfecto a través de una referencia irónica al lenguaje descrito por Godwin en su The Man in the Moon. Así escribía Cyrano:

«Ni sabía yo su lengua ni ellos entendían la mía, así que figuraos la proporción. Habéis de saber que en aquel país se emplean dos idiomas: de uno se sirven los grandes, el otro es propio del pueblo. El de los grandes no es más que una variación de tonos inarticulados, comparable casi a nuestra música cuando no se le añade letra. $\mathrm{Y}$ en verdad que es una invención a la par utilísima y harto agradable, pues, cuando se cansan de hablar o desdeñan prostituir la garganta en tal oficio, toman un laúd u otro instrumento, que les sirven tan bien como la voz para comunicar sus pensamientos, de suerte que a veces se reúnen hasta quince o veinte en compañía que discutirán una cuestión de teología o las dificultades de un pleito con un concierto de lo más armonioso que pueda acariciar la oreja. El segundo, el que utiliza el pueblo, se realiza por medio de sacudidas de los miembros, pero no como quizá se lo imagina uno, pues ciertas partes del cuerpo significan un discurso entero. Por ejemplo, al agitar un dedo, una mano, una oreja, u labio, un brazo, un carrillo, forman cada cual en particular una oración o un periodo con todos sus miembros. Otros movimientos sirven tan solo para designar palabras, como una arruga en la frente, los diferentes estremecimientos de los músculos, los giros de manos, el golpeteo de los pies, las contorsiones de brazos, de modo que cuando hablan, con la costumbre de andar siempre desnudos, sus miembros, habituados a gesticular las ideas, se menean tan enérgicamente que no parece hombre el que habla, sino cuerpo que tiembla» ${ }^{44}$.

El tono satírico de Cyrano respecto a las ideas expuestas por Godwin había quedado ya expresado en una anécdota curiosa y significativa: cuando el protagonista de Cyrano llega a la Luna, sus habitantes creen que es la hembra del animalito de la reina y deciden llevarle a vivir con su macho para que procreen; cuando se produce en el encuentro, resulta ser

\footnotetext{
${ }^{43}$ Cfr. GASSENDI, P., Philosophiae Epicuri Syntagma, Sectio III, cap. XX, «De motu voluntario, ac speciatim de loqutione, nominumque impositione», en Opera Omnia, edición de T. Gregory, vol. III, Stuttgart-Bad Cannstatt, 1964, 49-50.

${ }^{44}$ Ibid., 62-63.
} 
que el mono macho no es otro que el protagonista de la obra de Godwin que poco antes había llegado también a la Luna. Así describe Cyrano el encuentro entre la pareja:

«vi entrar, en medio de una manada de monos con gorguera y calzas, a un hombrecillo de constitución casi como la mía, pues andaba sobre dos pies. En cuanto me vio, me dirigió un Criado de vuesa merced [en español en el original]. [...] El hombrecillo aquel me contó que era europeo, oriundo de Castilla la Vieja, que con unos pájaros había encontrado la manera de hacerse elevar hasta el mundo de la luna donde nos encontrábamos; que, habiendo caído en manos de la reina, túvolo por mono, pues, por casualidad, en aquel país visten a los monos a la española, y, habiéndole hallado a su llegada vestido de aquel modo, no dudó ella [la reina] que fuera de la misma especie.

- Hay que decir — repuse [el protagonista] — que después de probarles toda clase de vestidos, no han hallado otro más ridículo y por eso los visten así, pues no guardan a esos animales sino por diversión.

— Eso es desconocer — dijo él — la dignidad de nuestra nación, en pro de la cual el universo produce hombres solo para que sean nuestros esclavos y para la cual la naturaleza sería incapaz de engendrar materia de burlas» ${ }^{45}$.

La interpretación que hace Cyrano del lenguaje era, en la línea de Gassendi, una especie de conciliación entre la tesis pagana y naturalista del origen del lenguaje de Lucrecio, por una parte, y el relato bíblico de la tradición cristiana, por otra. Era un lenguaje natural en cuanto a su génesis y en el primitivo estadio de expresión de sonidos no había interferencias entre ese lenguaje y la naturaleza debidos al mal empleo de la razón. En la posterior fase convencionalista había sido precisamente el erróneo uso de la razón el que había dado lugar a lenguajes defectuosos que no reflejaban la naturaleza de las cosas. Cyrano expresó esta idea de forma aún más clara en un pasaje de la segunda parte de su viaje cósmico: Les Etats et Empires du Soleil, publicado, también póstumamente, en 1662. Merece ser citado:

\footnotetext{
45 Ibid., 74-75. Una vez reunidos y enjaulados, ambos son atados con un cordel, haciéndoles dar volteretas y hacer muecas para entretener a los curiosos. En una de esas exhibiciones aparece un espectador que habla en griego y que cuenta al viajero lunar que una vez había estado en su tierra, que sabía que era francés y que dice ser el «demonio de Sócrates». Una vez abandonada la jaula, será este «demonio de Sócrates» el encargado de acompañar al protagonista en su recorrido por las regiones lunares, Ibid., 55 y ss
} 
«No me acuerdo si fui yo quien le habló primero, o si fue él quien me interrogó; pero conservo fresca la memoria, como si lo escuchara todavía, de lo que me refirió durante tres largas horas en una lengua que sé muy bien que jamás oí y que no guarda ninguna relación con las de este mundo, la cual, sin embargo, comprendí más de prisa y más inteligiblemente que la de mi nodriza. Me explicó, cuando inquirí por una cosa tan maravillosa, que en las ciencias había una Verdad, fuera de la cual siempre se alejaba uno de la fácil; que cuanto más se alejaba uno de esa verdad, tanto más se hallaba por bajo de la concepción y menos fácil era su inteligencia. 'De la misma manera -continuó- en la música no se encuentra jamás esta verdad sin que el alma, elevada al punto, no se incline ciegamente hacia ella. Nosotros no la vemos, pero sentimos que la naturaleza la ve; y sin poder comprender de qué suerte permanecemos absortos en ella, no deja de cautivarnos, aunque no sepamos indicar dónde está. Igual ocurre con las lenguas. Quien encuentra esta verdad de las letras, de las palabras y de su ilación, nunca puede quedar por bajo de su concepción: habla siempre conforme a su pensamiento; y es por no tener el conocimiento de este idioma perfecto por lo que os cortáis en vuestro discurso, al no conocer el orden ni las palabras que pueden explicar lo que imagináis'. Yo le dije que el primer hombre de nuestro mundo se había servido indudablemente de esa lengua matriz, porque el nombre que había impuesto a cada cosa declaraba su esencia. El me interrumpió y prosiguió: 'Tal lengua no sólo es necesaria para expresar todo lo que el espíritu concibe, sino que sin ella no es posible hacerse entender por todos. Como este idioma es el instinto o la vis de la naturaleza, debe ser inteligible para todo el que vive bajo el imperio de la naturaleza; de modo que si vos supierais ese idioma, podríais comunicar y exponer todos vuestros pensamientos a las bestias, y las bestias a vos todos los suyos, ya que es el lenguaje mismo de la naturaleza, por el cual se hace entender ésta de todos los animales. No os asombre, pues, la facilidad con que comprendéis el sentido de una lengua que jamás sonó en vuestros oídos. Cuando yo hablo, vuestra alma descubre en cada una de mis palabras esa Verdad que busca a tientas; y aunque su razón no la entienda, hay en ella una naturaleza que no podría dejar de hacerlo'.

— ¡Ah! —exclamé yo— ¿es sin duda por mediación de este enérgico idioma por lo que en otro tiempo nuestro primer padre conversaba con los animales y era entendido por ellos? Porque como le había sido dado el dominio sobre todas sus especies, éstas le obedecían, ya que formulaba sus mandatos en una lengua que les era conocida; y es por 
eso también (habiéndose perdido esa lengua matriz) por lo que las bestias no vienen ahora cuando las llamamos, debido a que ya no nos entienden». ${ }^{46}$

Las críticas a un lenguaje defectuoso que obstaculizaba el buen desarrollo del conocimiento científico y la crítica a las propuestas para resolver ese problema también aparecieron en otras utopías inspiradas en los viajes a nuevas tierras ${ }^{47}$. Así por ejemplo, bajo el pseudónimo de Mercurius Britannicus, el obispo Joseph Hall (1574-1656) escribió (entre 1605 y 1608) el Mundus alter et idem sive Terra Australis antehac semper incognita; Longis itineribus peregrini Academici nuperrime illustrata, una antiutopía cuyo objetivo fundamental era criticar a la sociedad londinense de su época y a la iglesia católica ${ }^{48}$. El texto de Hall es uno de los primeros sobre la Tierra Austral y en él se hacía explícita referencia a Abraham Ortelio, incluyendo el mapa de Australia que éste había publicado en su Thesaurus Geographius de 1587. En su viaje imaginario a las antípodas, Hall hacía una dura crítica de las instituciones europeas, de sus costumbres y valores. No escapaban tampoco a esta crítica la ciencia de la época y el lenguaje, dos temas que en la obra de Hall aparecían unidos. La imaginaria Academia Variniana del Mundus Alter estaba dividida en dos colegios, uno de escépticos inmunes a las sensaciones físicas y otro de filósofos obsesionados con la innovación que habían ideado un lenguaje nuevo y totalmente esotérico siguiendo los términos de Paracelso. De hecho uno de los rectores de la Academia Variniana se llamaba Bustius Hohenheimius.

\footnotetext{
${ }^{46}$ Se cita aquí según la edición española Los estados e imperios del Sol, trad. y notas de Juan Martín RuízWerner, Buenos Aires, Aguilar, 1968, 70-71.

47 Véase CoRnelius, P. (1965), Languages in 17th and Early 18th Century Imaginary Voyages, Ginevra, Droz; C. MARRONE, op. cit.

${ }^{48}$ Hall no escribió el texto con intención de publicarlo, sino como ejercicio de discusión en círculos universitarios. Parece ser que contra su voluntad, su amigo y colega William Knight lo publicó en 1607 añadiéndole un prefacio firmado por él. En 1609, y también en contra de la voluntad de Hall, Joseph Healey hizo una traducción inglesa con el titulo The Discovery of a New World or a Description of the South Indies by An English Mercury. Se volvió a publicar en 1643 junto con la Civitatis Solis de Tommaso Campanella (primera edición de 1623) y la New Atlantis de Francis Bacon (primera edición de 1627). Existe una edición inglesa reciente: Another World and Yet the Same: Bishop Joseph Hall's «Mundus Alter et Idem», ed. y trad. de John Millar Wands, New Haven/ Londres, Yale University Press, 1981 y una edición española: Un mundo distinto pero igual, traducción del latín, introducción y notas de Emilio García Estébanez, Madrid, Akal, 1994. Sobre Hall y su obra, véase KINLOCH, T.F. (1951), The Life and Works of Joseph Hall, 1574-1656, Nueva York, Staples Press; MCCABE, R. A. (1982), Joseph Hall, A Study in Satire and Meditation, Oxford, Oxford University Press; Negley, G. y Patrick, J.M. (eds.) (1952), The Quest for Utopia: An Anthology of Imaginary Societies, Nueva York, Henry Schuman; WANDS, J.M. (1980), The Early Printing History of Joseph Hall's Mundus Alter et Idem, en Papers of the Bibliographical Society of America, vol. 74, 1-12.
} 
Durante todo el siglo XVII, el problema del lenguaje seguiría siendo parte fundamental de la literatura utópica, siempre bajo la forma de viajes de navegación oceánicos o cósmicos a tierras desconocidas. Baste recordar la famosa y ya mencionada obra de Wilkins; mas también la Description of the Famous Kingdome of Macaria (1641), atribuida a Samuel Hartlib pero realmente escrita por su amigo Gabriel Plattes e inspirada en las reformas del lenguaje propuestas por Comenius, que aspiraban a crear un lenguaje natural no como recuperación de un lenguaje originario, sino natural porque reflejaría perfectamente las cualidades observables y las leyes de los fenómenos, de aquí la necesidad de investigar la naturaleza y a su vez la consecuencia de que el lenguaje derivado de ese conocimiento fuese el medio perfecto de transmisión del saber, lo cual coincidía con la propuesta de reforma del lenguaje lanzada por Francis Bacon ya desde su Advancement of Learning (1605) ${ }^{49}$. Ya más avanzado el siglo XVII, pero en la misma línea, aparecieron la obra de Gabriel de Foigny, La Terre Australe Connue (1676), donde se describía la lengua de los hermafroditas y la de Denis de Vairasse d'Alais, la Histoire des Sévarambes (1677) dedicada al idioma de los sevaritas. Todas ellas fueron incorporando las nuevas reflexiones sobre el lenguaje propuestas en el siglo XVII, ya muy diferentes de las del siglo anterior pero aún más ligadas al problema de la comunicación científica, especialmente a la cuestión de las clasificaciones de las cosas del mundo natural. Finalizado el siglo, seguiría vivo el debate sobre los caracteres reales, la necesidad de buscar o proyectar lenguajes que evitasen las confusiones lingüísticas y fuesen auténticos y perfectos instrumentos de comunicación científica. A aquellos debates y reflexiones sobre el lenguaje y su relación con la ciencia estaría dedicado uno de los más famosos libros de viajes del siglo XVII, Los viajes de Gulliver (1726), lleno de ironía ante las propuestas de sus contemporáneos ${ }^{50}$.

\footnotetext{
${ }^{49}$ Fue Hartlib el que llevó a Comenius a Inglaterra en 1641, el mismo año en el que Wilkins publicó su Mercury. Durante la estancia de Comenius en Inglaterra y hasta 1642, el círculo de Hartlib discutió intensamente sobre proyectos de lenguas universales, lo cual se presentaba a su vez como una condición para la creación de un colegio universal. Véase STRASSER, G. F. (2002), Closed and open languages: Samuel Hartlib's Involvement with Criptology and Universal Languages, y PRIVATSKA, J., Languages as the product and mediator of knowledge: the concept of J. A. Comenius, ambos en GreENGRASs, M. y LESLIE, M. (eds.) (2002), Samuel Hartlib and Universal Reformation: Studies in Intellectual Communication, Cambridge, Cambridge University Press, 151-161y 162-173 respectivamente.

50 Jonathan Swift estuvo especialmente interesado por el problema del lenguaje, lo cual quedó reflejado en muchos de sus escritos dedicados al tema, como por ejemplo el A Proposal for Correcting, Improving, and Ascertaining the English Tongue (1712). Véase C. MARRRONE, Le lingue utopiche, op. cit, 165 y ss.
} 